\title{
The search for novel bacteriophages aboard the International Space Station leads to the identification of two Bacillus species
}

\author{
Tristan R. Grams ${ }^{1}$, Deborah M. Tobiason ${ }^{1}$, Kasthuri Venkateswaran², and Andrea M. Henle ${ }^{1}$ \\ ${ }^{1}$ Department of Biology, Carthage College, Kenosha, WI, USA \\ ${ }^{2}$ Biotechnology and Planetary Protection Group, Jet Propulsion Laboratory, California Institute \\ of Technology, Pasadena, CA, USA
}

\begin{abstract}
The establishment of a permanent human presence on the International Space Station (ISS) raised new questions regarding the microbial burden inside this closed environment. High-efficiency particulate filters (HEPA) have been installed inside the ISS to reduce the level of harmful microbes that may affect an astronaut's health. While multiple studies have investigated bacteria within the ISS, no research has been done to detect the viruses that attack bacteria, bacteriophages, which can be used for biocontrol of bacterial levels. Bacteriophages specifically infect bacteria, replicate, and lyse the bacterial host cell, releasing new progeny. The goal of this interdisciplinary project is to isolate and characterize bacteriophages obtained from ISS HEPA filter samples. In the process of isolating bacteriophages, two Bacillus species were recovered and identified from the HEPA filters. This research allows for the potential application of bacteriophages in therapeutics and in the control of microbial burden in space.
\end{abstract}

\section{Introduction}

Since the establishment of the International Space Station (ISS) in 1998, several studies have investigated the bacterial presence in the station and its effect on astronaut health (La Duc et al., 2014; Checinska et al., 2015; Venkateswaran et al., 2014). High-efficiency particulate air (HEPA) filters have been implemented to mitigate harmful microbes in this enclosed space in an effort to improve air quality and prevent infection. Additionally, NASA and other space agencies have long withstanding interests in detecting and eliminating the presence of bacteria on the external surfaces of spacecraft (La Duc et al., 2014; Venkateswaran et al., 2004; Scoon et al., 1995; McKay et al., 1998; La Duc, et al. 2014). It is imperative that any missions to extraterrestrial surfaces do not carry contaminants from Earth to these surfaces. Not only could this have a detrimental effect on the extraterrestrial environment, but it could also hinder our ability to conclude whether or not there is presence of life in that environment. While several studies over the last decade have investigated the types of bacteria that can survive on external surfaces in space and that are found inside the ISS (Checinska et al., 2015; Venkateswaran et al., 2014; Castro et al., 2004), no one has yet searched for the presence of the natural predators and killers of bacteria, bacteriophages, and asked how bacteriophages are impacting the bacteria found in these environments.

On Earth, an estimated $10^{31}$ viruses exist that specifically infect bacteria (Clokie et al., 2011). These tiny viruses, called bacteriophages, attach to the cell walls of their bacterial hosts, inject their viral genome, and hijack the internal bacterial cell machinery to complete a replicative life cycle that allows them to burst from the bacterial cell, killing the bacteria in the process. Bacteriophages were initially discovered in 1917 as agents that kill bacteria (D’Herelle, 2007). In 
an era prior to antibiotics, these viruses were considered a therapeutic option for treating bacterial infections. In today's world, where antibiotic resistance is an emerging problem that leads to significant healthcare risks and costs, bacteriophage are once again being considered as an alternative therapeutic for targeting and controlling bacterial populations (Lin et al., 2017; Luepke et al., 2017).

Bacteriophages are the most abundant organisms on our planet. They can be isolated anywhere bacteria are present, including water and soil samples. It is estimated that there is at least one type of bacteriophage that infects each strain of bacteria, if not multiple types of bacteriophages (Comeau et al., 2008). Every day, an estimated $40 \%$ of oceanic bacteria are destroyed due to infection by bacteriophages (Danovaro et al., 2011). This relationship between bacteriophages and bacterial cells has direct implications on the population of bacteria in any environment. It is essential that the effects and dynamic interplay of this relationship be considered when investigating and reducing the presence of bacteria in space and in any closed habitats associated with spaceflight.

The highest amount of bacterial burden on the ISS consists of the phyla Actinobacteria, Firmicutes, and Proteobacteria (Checinska et al., 2015). The ISS environment has been shown to promote the growth of some Bacillus bacteria (Coil et al., 2016). Bacillus species have been used as a host in multiple bacteriophage studies and has been well characterized (Ackermann et al., 1978; Romig et al., 1961; Strauch et al., 1989). This study employed four Actinobacteria species and two Bacillus species for the isolation of bacteriophages from ISS HEPA filters.

To the best of our knowledge, no one has yet investigated the presence of bacteriophage in extraterrestrial environments or confined space habitats. This study is the first to undertake the task of isolating bacteriophages from the closed environment aboard the ISS. Initial attempts using four different Actinobacteria species as hosts for isolating bacteriophages were not successful; however, two bacterial species were recovered from the HEPA filters and identified as Bacillus lichenformis and Bacillus toyonensis. Bacteriophage isolation was attempted using the two Bacillus species recovered from the HEPA filters with no success. The genomes of any bacteriophages that are isolated in the future will be sequenced and annotated for genomic analysis, and the structure of these bacteriophages will also be studied using electron microscopy.

\section{Materials and Methods}

Bacteria: Gordonia terrae, Kocuria rosea, and Microbacterium foliorum were grown in peptone yeast calcium agar (PYCa) media. Mycobacterium smegmatis was grown in Luria broth media. ISS Bacillus toyonensis and Bacillus lichenformis were grown in standard nutrient broth. All culture plates were incubated at $37^{\circ} \mathrm{C}$, under atmospheric $\mathrm{O}_{2}$ and $\mathrm{CO}_{2}$.

The two (ISS) Bacillus species were isolated from ISS HEPA filters 1 (location: ISS Node 2) and 2 (location: ISS US Lab), which are filters that were installed and active on the ISS for 120 days and 882 days, respectively. HEPA-1 returned to Earth in 5/2011 and HEPA-2 in 1/2013. Both were kept in storage at $\sim 21{ }^{\circ} \mathrm{C}$ (room temperature) at NASA Jet Propulsion Laboratory (JPL) until analysis for this study in 6/2016. Sections of the HEPA filters were aseptically cut into 
smaller sections, approximately $1 \mathrm{~cm}^{2}$, and were immersed in PYCa media in sterile $50 \mathrm{~mL}$ conical tubes and placed on a shaking incubator overnight at $37^{\circ} \mathrm{C}, 180 \mathrm{rpm} .500 \mathrm{uL}$ of PYCa media was then spread onto PYCa plate and incubated at $37^{\circ} \mathrm{C}$ overnight. Colonies were purified on nutrient agar plates and incubated at $37^{\circ} \mathrm{C}$. The pure cultures were stained using a Gram-stain. Purified cultures of bacteria were identified using 16S rRNA sequencing. 16S rRNA sequencing results were queried with the NCBI BLAST tool (https://blast.ncbi.nlm.nih.gov/Blast.cgi) to determine the identity of isolated bacteria.

Bacteriophage Isolation: Approximately $1 \mathrm{~cm}^{2}$ sections of ISS HEPA filters along with control samples from JPL (HEPA filters from the JPL Spacecraft Assembly Facility (SAF), the JPL Physics Cleanroom, and a negative control floor wipe from the SAF) were placed in $25 \mathrm{~mL}$ phage buffer (10mM Tris $\mathrm{pH} 7.5,10 \mathrm{mM} \mathrm{MgSO}_{4}, 68 \mathrm{mM} \mathrm{NaCl}$ and $\left.1 \mathrm{mM} \mathrm{CaCl}_{2}\right), \mathrm{PYCa}$, or nutrient broth. Samples were shaken for 5 minutes and then filtered using $0.22 \mu \mathrm{m}$ Millipore filters. The filtered solution was used in either direct isolation or enrichment protocols. The direct isolation protocol was performed by adding $250 \mathrm{uL}$ of bacteria to $250 \mathrm{uL}$ of filtered sample. The samples were then incubated at room temperature for 20 minutes to allow any bacteriophages present a chance to attach to the bacterial host cells before $2.5 \mathrm{~mL}$ of top agar was added and the mixture poured onto a $10 \mathrm{~cm}$ diameter round agar plate. The plates were then incubated for 48 hours; the presence of plaques was monitored throughout the incubation time. The enrichment protocol consisted of mixing $250 \mathrm{uL}$ of bacteria with $3 \mathrm{~mL}$ of filtered sample. The samples were placed on shaking incubator at $37^{\circ} \mathrm{C}, 180 \mathrm{rpm}$, for 4 days. The samples were then filtered through a $0.22 \mu \mathrm{m}$ Millipore filter and $20 \mu \mathrm{L}$ was spotted onto prepared plates with the appropriate bacteria. The plates were then incubated for 48 hours at $37^{\circ} \mathrm{C}$ under atmospheric $\mathrm{O}_{2}$ and $\mathrm{CO}_{2}$.

\section{Results}

ISS Bacillus lichenformis and ISS Bacillus toyonensis were isolated from ISS HEPA filters 1 and 2 , respectively, during bacteriophage enrichment attempts. We rationalized that these bacteria may prove more suitable hosts for isolating bacteriophage from the ISS since they were recovered from that environment. Initial attempts at bacteriophage isolation using these species was unsuccessful.

Bacillus lichenformis has colonies that are $1 \mathrm{~mm}$ in diameter and rhizoid in form, while Bacillus toyonensis colonies are $3 \mathrm{~mm}$ in diameter and filamentous in form (Fig. 1). The Gram stain of Bacillus lichenformis and Bacillus toyonensis indicate that they are Gram-positive rods (Fig. 2). 16S rRNA sequencing results analyzed using the NCBI BLAST tool found that HEPA 1 bacteria was Bacillus lichenformis (99\% identity) while HEPA 2 was Bacillus toyonensis (99\% identity) (data not shown).

To date, no bacteriophages have been successfully isolated from HEPA 1 and 2 samples using the bacterial hosts Gordonia terrae, Kocuria rosea, Microbacterium foliorum, Mycobacterium smegmatis, ISS Bacillus toyonensis, and ISS Bacillus lichenformis. 


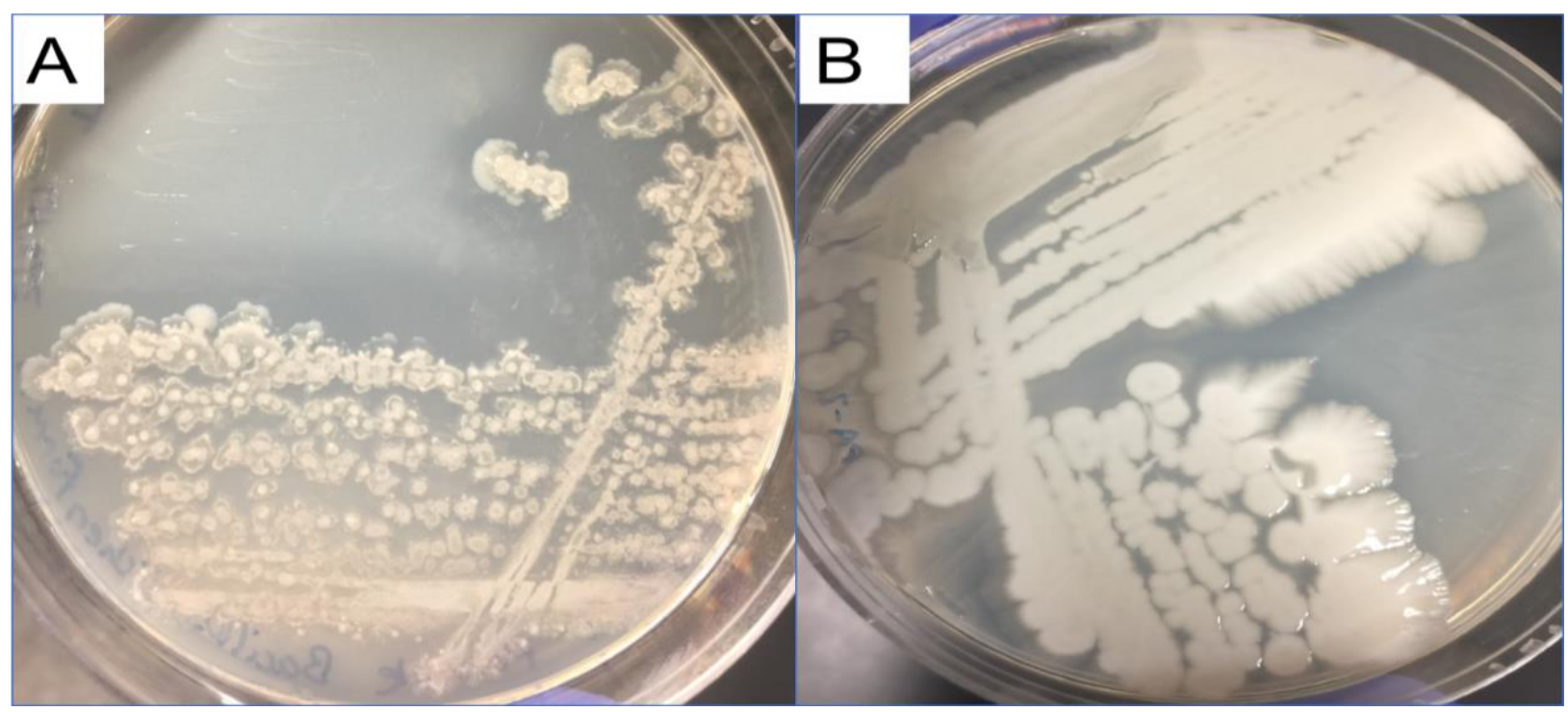

Figure 1. ISS HEPA 1 and HEPA 2 Bacterial Isolates Grown on Nutrient Agar.

(A) HEPA 1-PYCa colonies are $1 \mathrm{~mm}$ in diameter and rhizoid in form. These were later identified by $16 \mathrm{~S}$ rRNA sequencing as Bacillus lichenformis (data not shown). (B) HEPA 2-PYCa colonies are $3 \mathrm{~mm}$ in diameter and filamentous in form. These were later identified by $16 \mathrm{~S}$ rRNA sequencing as Bacillus toyonensis (data not shown). All images were captured after 24 hours of growth at $27^{\circ} \mathrm{C}$.

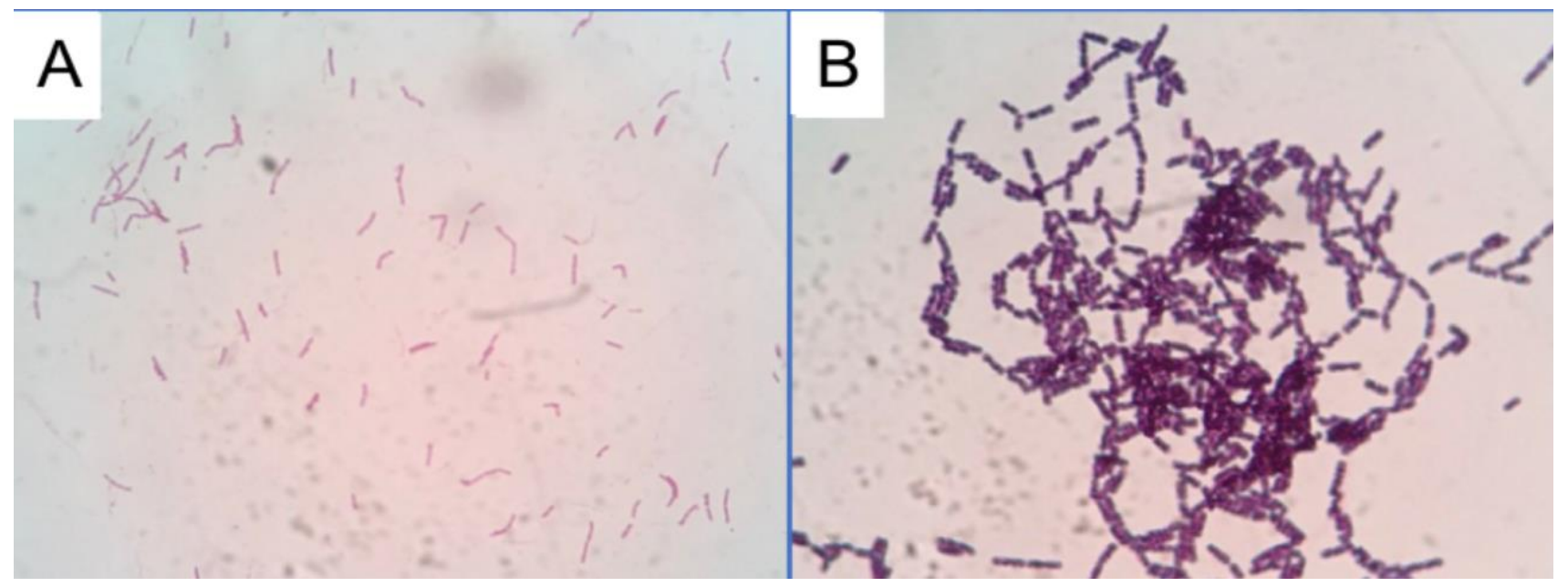

Figure 2. Gram Stain of Unknown Bacteria Isolated from HEPA 1 and HEPA 2.

(A) The gram-stain of HEPA 1-PYCa indicates a gram-positive, rod shaped bacteria. 16S rRNA sequencing identified this as Bacillus lichenformis (data not shown). (B) The gram-stain of HEPA 2-PYCa indicates a gram-positive, rod shaped bacteria. 16S rRNA sequencing identified this as Bacillus toyonensis (data not shown). All images were captured at 1000X total magnification using an Olympus CX31 compound microscope.

\section{Discussion}

The overall goal of this study was to isolate and characterize bacteriophages from a closed habitat of the ISS. At this point in time, we have not been able to find bacteriophages from two different ISS HEPA filter samples using 6 different bacterial hosts. One reason may be that we did not use the proper host for isolating the specific bacteriophage(s) that may be present on 
either of the filters. However, it is more likely that the age of the filters and the long duration in which they were stored at JPL ( $>5$ years for HEPA 1 , and $>3$ years for HEPA 2) prior to our study resulted in our inability to isolate bacteriophages using these procedures. Researchers in the bacteriophage field suggest storing bacteriophage stocks at $-80^{\circ} \mathrm{C}$ for long-term storage (Golec et al., 2011). The HEPA filters were stored at room temperature $\left(\sim 21^{\circ} \mathrm{C}\right)$ at NASA JPL in sealed bags. This particular storage temperature and the lack of nutrients available may have affected the viability of bacteria, therefore influencing the long-term stability of any bacteriophages infecting those host cells, therefore impacting our ability to successfully isolate bacteriophages from these samples. We hypothesize that any bacteriophages once present in these particular HEPA filters likely degraded while in storage. More recent HEPA filter samples or surface wipes returned from the ISS would be ideal for searching for bacteriophages. Our group is working on acquiring these samples for our future research.

Although we were not able to identify bacteriophages from the ISS HEPA filters, we did find two potentially novel bacteria, each of the genus Bacillus. Bacillus can undergo sporulation, making this type of bacteria difficult to eradicate from the ISS or spacecraft surfaces. The ability to sporulate likely allowed the bacteria to survive in storage for $>3$ years and allowed for successful isolation in this study. Bacillus species have also been previously reported to be found in abundance on the ISS (Checinska et al., 2015), which explains why we isolated Bacillus from the ISS HEPA filters. Further identification tests will need to be conducted to determine the potential novelty of any of these isolated bacteria.

Going forward, we plan to use recently acquired ISS surface wipes to isolate bacteriophages that may reside on the ISS. These ISS surface wipes were returned from the ISS on SpaceX's Dragon capsule in July 2017, and have been stored at $4^{\circ} \mathrm{C}$. We also plan to use common human commensals as hosts since astronauts are the primary source of bacteria present on the ISS. We hope that this revised approach of using more recently acquired ISS samples along with new bacterial hosts will yield the isolation of one or more bacteriophages from the ISS environment. Bacteriophages isolated from ISS samples will be studied further using genomic and structural assays. These results will be compared to bacteriophages isolated from samples on Earth and can be used to determine the effects of the ISS environment (ie. radiation or microgravity) on the bacteriophage.

Bacteriophages are host-specific natural enemies of bacteria. These viruses have distinct applications, such as biocontrol or eradication of unwanted or harmful bacterial species and therapeutic control of pathogens. Bacteriophages are currently used in the food and agricultural industry to prevent foodborne pathogens from contaminating the food supply (Kazi et al., 2016). Efficient eradication of bacterial pathogens with the use of bacteriophages may be an effective way to control harmful bacteria found in closed environments such as the ISS and could be of great benefit to astronaut health. Bacteriophages show much potential as a therapeutic particularly in long-term spaceflight since they can be continuously replenished provided a bacterial host is available. This is in contrast to antibiotics, which would need to be synthesized or resupplied during long duration space missions. Our future research will focus on characterizing the role of bacteriophages in the ISS environment and exploring the potential 
application and feasibility of these viruses as therapeutics during spaceflight and as a means of biocontrol in space.

\section{Acknowledgments}

The authors would like to thank the Wisconsin Space Grant Consortium for funding this project through a grant in the Research Infrastructure Program. The authors would also like to thank the Division of Natural and Social Sciences at Carthage College for their ongoing support and NASA's Jet Propulsion Laboratory for hosting us during the initial sample collection.

\section{References}

Ackermann, H.W., et al. (1978), Partial characterization of a cubic Bacillus phage. Can J Micobiol., 24, 986-993.

Castro, V. A., et al. (2004), Microbial characterization during the early habitation of the International Space Station. Microb. Ecol., 47, 119-126.

Checinska, A., et al. (2015), Microbiomes of the dust particles collected from the International Space Station and Spacecraft Assembly Facilities. Microbiome, 3, 50.

Clokie, M. R., et al. (2011), Phages in nature. Bacteriophage, 1, 31-45.

Comeau, A. M., et al. (2008), Exploring the prokaryotic virosphere. Res. Microbiol., 159, 306313.

Danovaro, R., et al. (2011), Marine viruses and global climate change. FEMS Microbiol. Rev., 35, 993-1034.

Coil, DA., et al. (2016), Growth of 48 built environment bacterial isolates on board the International Space Station (ISS). PeerJ, 4:e1842.

D'Herelle, F. (2007), On an invisible microbe antagonistic toward dysenteric bacilli: brief note by Mr. F. D’Herelle, presented by Mr. Roux. 1917. Res. Microbiol. 158, 553-554.

Golec, P., et al. (2011), A reliable method for storage of tailed phages. Journal of Microbiological Methods, 84(3), 486-489.

Kazi, M., and Annapure, U.S., (2016), Bacteriophage biocontrol of foodborne pathogens. Journal of Food Science and Technology., 53(3), 1355-1362.

La Duc, M. T., et al., (2004), Microbial monitoring of spacecraft and associated environments. Microb. Ecol., 47, 150-158.

La Duc, M. T., et al., (2014), A Genetic Inventory of Spacecraft and Associated Surfaces. Astrobiology, 14, 15-23.

Lin, D.M., et al., (2017), Phage therapy: An alternative to antibiotics in the age of multi-drug resistance. World J Gastrointest Pharmacol Ther., 8(3),162. 
Luepke, K.H., et al., (2017), Past, Present, and Future of Antibacterial Economics: Increasing Bacterial Resistance, Limited Antibiotic Pipeline, and Societal Implications. Pharmacotherapy, 37(1), 71-84.

McKay, C. P., (1998), Past, present, and future life on Mars. Gravit. Space Biol. Bull., 11, 41-50. Romig, W.R. and Brodetsky, A.M., (1961), Isolation and preliminary characterization of bacteriophages for Bacillus subtilis. J Bacteriol., 82, 135-141.

Scoon, G. E., et al., (1995), Planetary environment protection ID no: F3.3-M.1.05 implications for the development of a network of surface stations on Mars. Adv. Space Res., 15, 261-272.

Strauch, M.A., et al., (1989), The transition state transcription regulator abrB of Bacillus subtilis is a DNA binding protein. EMBO J, 8, 1615-1621.

Venkateswaran, K., et al., (2014), International Space Station environmental microbiome microbial inventories of ISS filter debris. Appl. Microbiol. Biotechnol., 98, 6453-6466.

Venkateswaran, K., et al., (2004), Evaluation of various cleaning methods to remove bacillus spores from spacecraft hardware materials. Astrobiology, 4, 377-390. 